\title{
The 24th International Symposium on Separation Sciences (ISSS2018)
}

\author{
Milan Hutta ${ }^{1}$. Dušan Berek ${ }^{2}$ \\ Published online: 3 April 2019 \\ ๑) Springer-Verlag GmbH Germany, part of Springer Nature 2019
}

The 24th International Symposium on Separation Sciences (ISSS2018) which was held jointly with the 21st International Conference of Analytical Methods and Human Health (AMHH) was held in Jasna, Slovakia on June 17-20, 2018.

The main organizer of the event was the Department of Analytical Chemistry, Faculty of Natural Sciences of Comenius University in Bratislava, Slovakia in cooperation with the Central European Group for Separation Sciences, the Expert Group for Chromatography and Electrophoresis of the Slovak Chemical Society, the European Separation Science Society and the Slovak Vacuum Society.

The scientific program was focused on the latest trends and achievements in analytical separation methods.

The conference topics were divided into several groups:

- Fundamental aspects of separation sciences • Advances in separation techniques $\bullet$ Novel instrumentation in separation sciences $\bullet$ Multidimensional analytical methods $\bullet$ Sample preparation techniques $\bullet$ Drug analysis and bioanalysis • Forensic analysis • Environmental and industrial application -Analytical chemistry methods and human health • Food and consumer product safety $\bullet$ Chemometry and data processing.

The event was attended by more than 180 participants, from 21 countries, including representatives of 8 exhibiting companies. There were 54 lectures, including 6 plenary and 16 invited lectures from speakers from renowned academic and research institutions. The conference was sponsored by

Published in the topical collection 24th International Symposium on Separation Sciences combined with 21st International Conference Analytical Methods and Human Health with guest editors Milan Hutta and Dušan Berek.

Milan Hutta

milan.hutta@uniba.sk

Dušan Berek

Dusan.Berek@savba.sk

1 Department of Analytical Chemistry, Faculty of Natural Sciences, Comenius University, Bratislava, Slovakia

2 Polymer Institute, Slovak Academy of Sciences, Bratislava, Slovakia several corporate partners, which contributed directly to the program (lectures and exhibition of their products), as well as by local media.118 posters were presented during the extended poster sessions. Numerous young researchers attended the meeting. They enjoyed special conditions such as reduced fee and also the possibility to present their research. The latter met with the keen interest of both speakers and audience. From the presented lectures and posters, the Department of Analytical Chemistry FNS, CU Bratislava published the Proceedings of Abstracts, 210 pages. CASSS provided travel grants for $\mathrm{PhD}$ candidates and academic postdocs presenting posters and/or talks at ISSS 2018.

According to the numerous participants, the ISSS 2018 had a high scientific level. The participants also highlighted the social aspects of the event, the friendly atmosphere and the environment of the conference. The place for informal contacts and business meetings were the pleasant rooms of the Wellness Grand **** Hotel, Jasna. Part of the social program was a trip to the top of Chopok Mountain over 2,000 m altitude with modern cable cabin and a social evening accompanied by Slovak national music at the hotel, which was sponsored by Pragolab Company.

Last but not least, we would like to thank all the sponsors for their financial and material assistance, which helped us to ensure the success of the event. Three applicants were chosen to receive CASSS grants, two best posters of young scientists were awarded by book vouchers from CHROMATOGRAPHIA and two best lectures of young scientists were awarded by free attendance at ISSS 2019.

For more information, please visit the conference website http://www.isss2018.sk. The 25th International Symposium on Separation Sciences ISSS 2019 will take place on 15-18 September 2019 in Lodz (Poland) at TUL Sports and Education Centre "Sports Bay", TUL's campus on Politechniki 10 Street. (https://www.isss2019.p.lodz.pl/).

Publisher's Note Springer Nature remains neutral with regard to jurisdictional claims in published maps and institutional affiliations. 